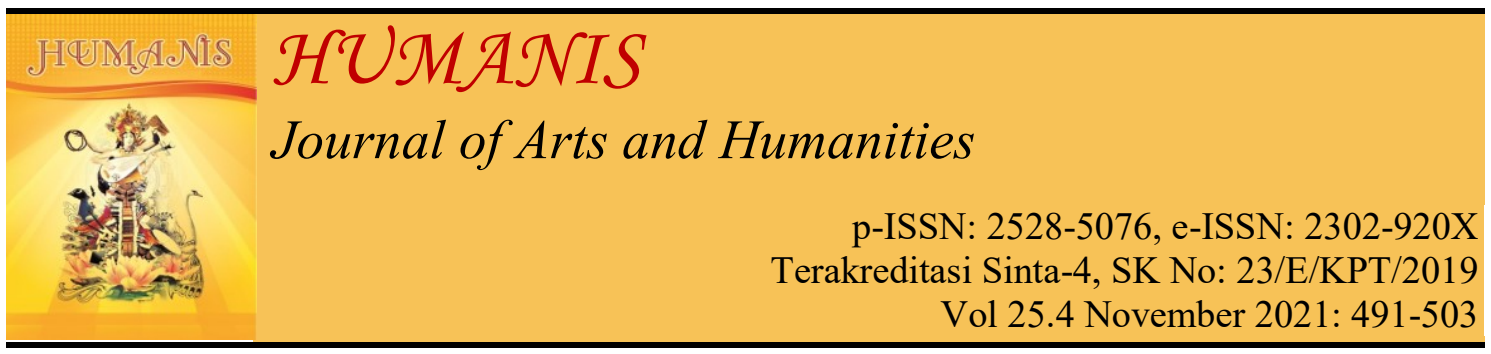

\title{
Geguritan Cokli: Analisis Sosiologi Sastra
}

\author{
Ida Bagus Gede Paramita \\ STAH Negeri Mpu Kuturan Singaraja, Bali, Indonesia \\ Email korespondensi: ibgparamita@stahnmpukuturan.ac.id
}

\begin{tabular}{|c|c|}
\hline Info Artikel & Abstract \\
\hline $\begin{array}{l}\text { Masuk: } 27 \text { Juni } 2021 \\
\text { Revisi: } 10 \text { Agustus } 2021 \\
\text { Diterima: } 15 \text { September } 2021 \\
\text { Keywords: geguritan cokli, } \\
\text { sociological analysis }\end{array}$ & $\begin{array}{l}\text { Research on Geguritan cokli uses a sociological analysis. The } \\
\text { approach used is a calibative approach. Data collection uses } \\
\text { the method of reading, translating and listening to Cokli's } \\
\text { Geguritan text. The method of analysis, carried out in a } \\
\text { descriptive-qualitative way by using the working stages of the } \\
\text { theory of sociology of literature and combined with the theory } \\
\text { of structure. The results of the analysis are presented in a } \\
\text { systematic and structured manner. The results of this study } \\
\text { provide an answer that the existence of a literary work can be a } \\
\text { reflection of the state of society at that time, although there are } \\
\text { some things that are sometimes no longer relevant to use. }\end{array}$ \\
\hline & Abstrak \\
\hline $\begin{array}{l}\text { Kata kunci: geguritan cokli, } \\
\text { analisis sosiologi sastra }\end{array}$ & $\begin{array}{l}\text { Penelitian terhadap Geguritan cokli menggunakan analisis } \\
\text { sosiologi sastra. Pendekatan yang dipergunakan adalah } \\
\text { pendeketan kialitatif. Pengumpulan data menggunakan metode }\end{array}$ \\
\hline $\begin{array}{l}\text { Corresponding Author: } \\
\text { Ida Bagus Gede Paramita } \\
\text { Email: } \\
\text { ibgparamita@stahnmpukuturan } \\
\text { ac.id }\end{array}$ & $\begin{array}{l}\text { membaca, menerjemahkan dan menyimak teks Geguritan Cokli. } \\
\text { Metode analisis, dilakukan dengan cara dekriptif-kualitatif } \\
\text { dengan menggunakan tahapan kerja teori sosiologi sastra dan } \\
\text { dipadukan dengan teori struktur. Hasil analisis disajikan } \\
\text { secara sistematis dan terstruktur. Hasil penelitian ini } \\
\text { memberikan jawaban bahwa keberadaan sebuah karya sastra }\end{array}$ \\
\hline $\begin{array}{l}\text { DOI: } \\
\text { https://doi.org/10.24843/JH.20 } \\
\text { 21.v25.i04.p09 }\end{array}$ & $\begin{array}{l}\text { bisa menjadi cerminan keadaan masyarakat saat itu, walaupun } \\
\text { ada beberapa hal yang terkadang sudah tidak relevan lagi } \\
\text { dipergunakan. }\end{array}$ \\
\hline
\end{tabular}

\section{PENDAHULUAN}

Geguritan adalah salah satu karya sastra tradisional dan mendapat tempat di hati masyarakat Bali, ini disebabkan oleh penggunaan media bahasa Bali ataupun bahasa Kawi, yang memudahkan masyarakat dalam penangkapan makna atau pemahaman keseluruhan karya tersebut. Geguritan mempunyai sistem konvensi sastra tertentu. Sistem konvensi sastra yang dimiliki Geguritan cukup ketat (Agastya, 1980:) Membaca sebuah karya sastra Geguritan tidaklah dapat seperti membaca sebuah karya sastra prosa melainkan harus dilagukan. Tradisi melagukan Geguritan yang di Bali disebut dengan aktifitas mabebasan. Aktifitas ini menjadi hal yang penting dan menarik karena kandungan isi dari karya bisa dipahami lebih mudah oleh masyarakat. 
Geguritan juga memiliki sistem konvensi yang cukup ketat yakni, dibangun oleh pupuh, dan pupuh itu diikat oleh beberapa syarat. Syarat-syarat pupuh tersebut biasa disebut pada lingsa yaitu banyaknya baris dalam tiap bait (pada) dan banyaknya suku kata dalam tiap-tiap baris. Karena itu dalam proses kepengarangan sebuah pupuh biasanya pengarang mengarang sambil melagukan. Atau sastra Geguritan diciptakan sambil melagukannya (Agastya, 1980). Geguritan yang dilagukan dalam tradisi mabebasan selain berfungsi sebagai sarana penghibur, juga memiliki fungsi sebagai sarana pendidikan karena didalamnya Geguritan kaya dengan ajaran etika, filsafat yang bisa dijadikan suri tauladan dalam menjalani kehidupan. (Luxemburg, 1980) menyatakan Karya sastra akan berperan sebagai guru, karya sastra akan dapat menunjukkan jalan keluar bagi kekurangan-kekurangan dalam suatu tata kemasyarakatan agar berjalan ke arah yang lebih baik.

Kekayaan makna dari Geguritan inilah yang membuat karya ini tetap lestari baik itu dalam tradisi mabebasan maupun dalam aktifitas kepengarangan. Banyak karya Geguritan baru yang tercipta salah satunya adalah Geguritan Cokli. Geguritan Cokli merupakan karya teranyar dari I Gusti Gede Djelantik Santha. Beliau berasala dari Dusun Bukit Buung, Kesiman, Denpasar. Karya ini mempunyai struktur naratif yang lengkap serta mengandung aspek sosial masyarakat. Sedangkan dari bentuknya Geguritan Cokli menggunakan berbagai jenis pupuh yaitu Sinom, Ginada, Kumambang, Durma, Pangkur, Semarandana, Dangdang, Mijil, Pucung, Adri, Ginanti, Demung, Megatruh. (Bagus, 1991) menyatakan, pemakaian pupuh dapat dibedakan menjadi tiga : (1) Geguritan yang memakai satu jenis pupuh, (2) Geguritan yang memakai banyak jenis pupuh tanpa adanya pengulangan pada bagian lain, (3)
Geguritan yang memakai berbagai jenis pupuh dengan adanya pengulangan pada bagian lain. Berdasarkan pendapat di atas jadi Geguritan Cokli merupakan Geguritan yang memakai berbagai jenis pupuh tanpa adanya pengulangan pada bagian lainnya.

Geguritan Cokli ide keperangannya adalah dari cerita (satua) nenek pengarang. Cerita inilah kemudian dirangkai dan disusun menjadi karya sastra Geguritan. Karya ini menceritakan kisah percintaan tak sampai antara Ayu Cokli dengan Gusti Ngurah Sibetan. Beliau rela mengorbankan cintanya kepada Gusti Ngurah Sibetan karena masih ingin mempelajari ajaran yoga untuk mendapat kesempurnaan hidup (moksa). Akhirnya Ayu Cokli mencapai Moksa karena keseriusannya mempelajari ajaran yoga tersebut. Geguritan ini sarat akan aspek-aspek sosial masyarakat yang mengungkap tentang aspek keagamaan dan ajaran Ketuhanan yang sangat kental.

Berdasarkan hal tersebut di atas maka penelitian terhadap Geguritan cokli ini sangat layak untuk dilksanakan, karena fungsi edukasi dengan pembawaan hiburan yang bisa dengan mudah dipahami oleh masyarakat awam sekalipun. Nilai-nilai etika dan filosofi yang yang terkandung dalam Geguritan Cokli ini juga sangat dalam sehingga sangat baik dijadikan sebuah literasi sebagai formulasi peningkatan kualitas diri baik itu untuk masyarakat penikmat Geguritan ataupun masyarakat umum.

\section{METODE DAN TEORI}

Penelitian terhadap Geguritan Cokli dengan menganalisis aspek sosiologi sastra menggunakan pendekatan kualitatif. Sumber data dalam penelitian adalah data primer dan data sekuder. Data primer adalah teks Geguritan Cokli sedangkan data sekunder adalah data atau informasi yang diambil dari buku, jurnal 
ilmiah, internet, arsip, foto dan lain-lain yang dapat membantu dan menunjang penulisan artikel ilmiah ini Pengumpulan data menggunakan metode membaca, menerjemahkan dan menyimak teks Geguritan Cokli. Data yang telah terkumpul dianalisis dengan menggunakan metode dekriptif-analitik dengan menggunakan tahapan kerja teori strukturalisme-sosiologi.

Geguritan adalah salah satu bentuk karya sastra. Sebagai sebuah karya sastra, Geguritan memiliki struktur yang yang dibangun oleh keterkaitan hubungan antar unsurnya sebagi sesuatu yang utuh dan tidak bisa saling ditiadakan (Teeuw, 1983; Endraswara, 2013). Teori sosiologi sastra merupakan pendekatan terhadap sastra yang mempertimbangkan segi-segi kemasyarakatan). Sosiologi sastra dalam pengertian di atas mencakup berbagai aspek kehidupan di dalam masyarakat. Namun, semua pandangan tersebut menunjukkan satu kesamaan perhatian terhadap sastra sebagai lembaga sosial yang diciptakan oleh sastrawan (Damono, 1978)

\section{HASIL DAN PEMBAHASAN}

\section{Proses Penciptaan Geguritan Cokli}

Karya sastra adalah suatu ide kreatif pengarang dalam menuangkan ide-idenya dalam jalinan cerita dengan menggunakan bahasa sebagai medianya. Menarik atau tidaknya sebuah karya sastra tergantung dari kepintaran pengarang menjalin cerita. Sebuah karya yang menarik biasanya akan mendorong pembacanya untuk mengetahui proses penciptaan karya tersebut. Beberapa pertanyaan akan muncul, apakah karya ini merupakan pengalaman pengarang atau merupakan karya fiksi belaka.

Terciptanya Geguritan Cokli bukan merupakan pengalaman ataupun sebuah karangan fiktif melainkan sebuah silsilah keturunan dari pengarang. Penyebab Djelantik Santha mengarang Geguritan ini cukup unik yaitu wangsit dari nenek beliau Ratu Niang Pande yang mendatanginya lewat mimpi. Dalam mimpinya inilah Djelantik Santha diperintahkan untuk menuliskan silsilah leluhunya.

Mengenai ide yang dituangkan pengarang didapat dari satua-satua yang diceritakan neneknya ketika Djelantik Santha masih kecil. Dari satua-satua itulah kemudian Djelantik Santha menuliskannya dalam sebuah Geguritan. Dalam proses penulisan karya ini terkesan cukup unik karena karya ini ditulis dari awal sampai selesai dikerjakan dari jam 2 subuh. Menurut pengarang bagaikan ada yang membangunkan beliau pada jam tersebut untuk kembali mengerjakan karya Geguritan Cokli ini. Beliau terasa ditunggui saat menulis Geguritan ini. Bahkan ketika ceritanya sampai pada tahap sedih Djelantik Santha menangis melagukan pupuh-pupuhnya. Setelah selesai menyusun pupuh-pupuh yang membangun geguritan Cokli. Barulah kemudian beliau mengedit padalingsanya. Itulah yang beliau alami saat menulis geguritan ini hingga akhirnya selesai dikerjakan pada tanggal 7 Juni 2007. Selain ide-ide dari satua faktor imajinasi juga sangat mempengaruhi karya geguritan ini. Ideide yang banyak ditonjolkan adalah mengenai bidang keagamaan dan cara menjalani hidup berdasarkan Catur Asrama. Ide dalam bidang keagamaan banyak dilukiskan tentang dengan ajaranajaran filsafat dan moral yang dapat dijadikan pedoman hidup. Ide percintaan pun dilukiskan pengarang sebagai pemanis bait demi bait pupuh yang membangun Geguritan Cokli.

\section{Analisis Struktur Geguritan Cokli Insiden}

Insiden adalah kejadian atau peristiwa yang terkandung dalam cerita besar atau kecil. Secara keseluruhan 
insiden-insiden ini menjadi kerangka yang membangun atau membentuk struktur cerita. Berikut beberapa insiden yang terdapat dalam Geguritan cokli:

a. Insiden pertama dalam Geguritan Cokli adalah menceritakan tentang Gusti Wayan Banjar yang tinggal di Puri Dalem Jawi beserta dengan putraputrinya yang sangat cantik dan tampan yaitu Gusti Ayu Cokli, Gusti Nyoman Banjar dan Gusti Ketut Bona. Gusti Ayu Cokli disukai oleh anak adipate agung yang bernama Gusti Ngurah Sibetan.

b. Insiden kedua, Gusti Ayu Cokli diajak bertirta yatra ke Pura Pucaksari. Di tempat tersebut pula Gusti Ngurah Sibetan mengutarakan isi hatinya kepada Gusti Ayu Cokli. Akan tetapi ditolak dengan alasan masih ingin belajar dan menuntut ilmu

c. Insiden ketiga, menceritakan Gusti Nyoman Banjar menjalin cibta dengan Gusti Ayu Rai dan memohon izin kepada orang tuanya agar diizinkan menikah akan tetapi ditolak dengan alasan kakaknya Gusti Ayu Cokli belum menikah. Karena sikap keras Gusti Nyoman Banjar akhirnya mereka pun dinikahkan.

d. Insiden keempat adalah, pada saat upacara agung di Besakih yang yang berada di Pusar Tasik di Puncak Gunung Agung, Gusti Ayu Cokli bersama Gusti Ngurah Sibetan mendapat kesempatan mempersembahkan pakelem. Setelah sampai di Pusar Tasik lalu beliau menghaturkan banten pakelem kemudian duduk dan melakukan Yoga. Saat melakukan yoga tiba-tiba datang seekor kera putih dan memberikan batu manik yang berwarna hitam dan putih. Ditempat itu pula Gusti Ngurah Sibetan kembali merayu Gusti Ayu Cokli agar bersedia dinikahi, tetapi tetap saja ditolak dengan alasan dia masih ingin menuntut ilmu. e. Insiden kelima yaitu setelah ditanyakan oleh orang tuanya, kenapa Gusti Ayu Cokli tidak mau menikah dengan Ngurah Sibetan, ternyata ia punya alasan lain yaitu dia sudah terlanjur mengabdikan dirinya menjadi juru sapuh di Gunung Agung. Karena itulah lebih baik Gusti Ngurah Sibetan mencari orang lain untuk diperistri.

f. Insiden keenam adalah, Gusti Ayu Cokli menulis surat di lontar yang berisi bahwa ia tidak bisa menikah dengan Gusti Ngurah Sibetan. Gusti Ayu Cokli mengharapkan agar Gusti Ngurah Sibetan tidak menyesal mencintainya walaupun akhirnya tidak berjodoh. Setelah membaca surat itu sangat sedih hati Gusti Ngurah Sibetan.

g. Insiden ketujuh adalah, pada saat tilem kapitu hari Siwaratri Gusti Ayu Cokli meminta izin kepada orang tuanya ingin bertapa ke Pura Pasar Agung dengan membawa 2 orang pengiring untuk mengantarnya. Sesampainya di Pura Pasar Agung Gusti Ayu Cokli menyuruh agar pengiringnya pulang dan berpesan jika gelung kori di Puri patah dan jatuh dia diminta dijemput kembali yang menandakan beliau telah meninggal. Saat itulah Gusti Ngurah Sibetan menjemputnya dan menemukannya telah menjadi mayat dan dipercaya telah mencapai moksa.

h. Insiden kedelapan adalah, Gusti Ayu Cokli meninggalkan surat dari daun lontar dan sebuah pengrupak. Dalam suratnya berisi agar mayatnya dibakar di jaba tengah, yang kedua agar pengrupak yang ditinggalkan agar diberikan kepada generasi penerusnya, ketiga agar Gusti Ngurah Sibetan segera menikah.
Alur
Alur diartikan sebagai suatu jalinan cerita, yakni bagaimana si pengarang menyusun peristiwa-peristiwa dalam ceritanya itu bersebab akibat dan 
peristiwa itu hendaknya merupakan akibat logis dari suatu peristiwa sebelumnya. Menurut S. Tarif (Tarigan, 1986) ada lima unsur yang menyebabkan alur berkembang, yaitu: 1) Situation (pengarang melukiskan suatu keadaan); 2) Generating Circumstances (peristiwa mulai bergerak); 3) Rising Action (keadaan yang mulai memuncak); 4) Climax (peristiwa sudah mencapai klimaks); 5) Denoument (pemecahan persoalan dari peristiwa-peristiwa).

Unsur Situation, Menceritakan tokoh-tokoh yang tinggal di Dalem Jawi yaitu Gusti Wayan Banjar dan istrinya yang mempunyai anak Gusti Ayu Cokli, Gusti Nyoman Banjar, dan Gusti Ketut Bona yang kesemuanya mempunyai paras yang amat cantik dan tampan. Selain itu pengarang juga menggambarkan telah ada tali percintaan antara Gusti Ayu Cokli dengan Gusti Ngurah Sibetan yang merupakan anak dari Adipati Agung. Karena masih bersaudara mereka sangat gampang untuk bertemu baik itu untuk memadu kasih, bertirta yatra, berburu maupun jalan-jalan.

Generating Circumstances, hal ini dimulai saat bulan ke-3 pada hari Saraswati Gusti Ngurah Sibetan mengajak Gusti Ayu Cokli metirta yatra ke Pura Pucaksari. Dengan senang hati Gusti Ayu Cokli menyanggupi permintaan kekasihnya. rombongan Ayu Cokli yang akan bertirta yatra ke Pura Pucaksari. Setelah sampai di Pura mereka melakukan persembahyanga. Malam harinya Gusti Ngurah Sibetan mengutarakan maksudnya untuk memperistri Gusti Ayu Cokli. Akan tetapi Ayu Cokli menolak dengan alasan belum siap karena masih ingin menuntut ilmu. Pada bagian lain Gusti Nyoman Banjar rupanya telah menjalin cinta dengan Gusti Ayu Rai. Perasaan mereka tumbuh karena sering bertemu yaitu saat Gusti Ayu Rai sering ke Jero Dalem Jawi belajar menenun dan sastra pada Gusti Ayu Cokli.

Rising Action, terjadi ketika untuk kedua kalinya Gusti Ngurah Sibetan merayu Gusti Ayu Cokli di Jero Dalem Jawi, akan tetapi tetap saja ditolak dengan alasan beliau telah berjanji pada diri sendiri ingin menuntun ilmu hingga tuntas. Karena terus didesak Gusti Ayu Cokli kesal dan menyuruh Gusti Ngurah Sibetan untuk pulang. Kemudian orang tuanya Gusti Ayu Cokli menanyakan kenapa ia tidak mau menikah dengan Ngurah Sibetan, ternyata Gusti Ayu Cokli punya alasan lain yaitu di sudah terlanjur mengabdikan dirinya menjadi juru sapuh di Gunung Agung. Gusti Ayu Cokli menuliskan surat kepada Gusti Ngurah Sibetan diatas daun lontar yang berisi kalau ia tidak bisa menikah dengan Gusti Ngurah Sibetan dan menyuruh ayahnya membawa ke Puri Agung. Setelah membaca surat itu sangat sedihlah hati dari Gusti ngurah Sibetan karena putus cinta dengan Gusti Ayu Cokli.

Climax, ketika tilem katujuh hari Siwa Ratri Ayu Cokli meminta izin kepada orang tuanya ingin bertapa ke pura Pasar Agung dengan membawa 2 orang pengiring untuk mengantarnya yaitu Mangku Jarni dan Pan Jarna dari Palamadon. Sesampainya di pura Pasar Agung Ayu Cokli menyuruh agar pengiringnya pulang dan berpesan jika gelung kori di puri patah dan jatuh dia diminta dijemput kembali yang menandakan beliau telah meninggal. Ternyata memang benar seperti apa yang dipesankan oleh Gusti Ayu Cokli, gelung Kori Agung telah patah. Saat itu pula Gusti Ngurah Sibetan mendengar suara dari hutan minta tolong. Lalu segeralah ia pergi ke Jero Dalem Jawa untuk menanyakan apa arti gelung Kori Agung yang telah patah itu. Setelah diberitahu oleh ayah Cokli betapa sedih hati Gusti Ngurah Sibetan. Saat itulah Gusti Ngurah Sibetan menjemputnya dan 
menemukannya telah menjadi mayat dan dipercaya telah mencapai moksa.

Denoument cerita selanjutnya menurun yaitu ketika Gusti Ngurah Sibetan terlarut dalam kesedihan atas meninggalnya Cokli. Melihat hal itu Ayahandanya menasehati dan akhirnya Gusti Ngurah Sibetan pun menikah sesuai dengan pesan terakhir yang dituliskan Gusti Ayu Cokli. Akhirnya beliau menikah dengan Gusti Ayu Pandhe yang masih ada hubungan kerabat dengan ibunya. Setelah menikah akhirnya Gusti Ngurah Sibetan menjadi Adipati. Dari hasil pernikahannya ini beliau dikaruniai seorang putra dan putri. Setelah mempunyai keturunan akhirnya suami istri ini ditasbih menjadi Rsi.

\section{Tokoh dan Penokohan}

Tokoh Utama dalam Geguritan Cokli adalah Gusti Ayu Cokli dan Gusti Ngurah Sibetan Sibetan. Tokoh Gusti Ayu Cokli digambarkan sebagai seorang gadis yang memiliki paras cantik, berperilaku baik, taat sembahyang dan keras pendirian.

Mangkin malih caritayang, né malinggih maring Puri, wantah Gusti Wayan Banjar, madué putri listu ayu, kadi sekar nedeng kembang, kapeséngin, Ayu Alit Cokli kocap.

Terjemahan :

Sekarang diceritakan lagi, yang bertempat tinggal di Puri, hanya I Gusti Wayan Banjar, mempunyai putri yang sangat cantik, bagaikan bunga yang sedang mekar, diberi nama, Ayu Alit Cokli. ( Pupuh Ginada bait 6 )

Ngurah Sibetan mamahbah, Adi Ayu, kenken papinehe mangkin, yusa sampun sanga likur, nyandang samopun masomah, naging adi, kari mangretin kahyun, apang tan enggalan wayah, ngiring ja alaki rabi.
Terjemahan :

Ngurah Sibetan memulai, adinda, bagaimana sekarang, usia sudah 29 tahun, sudah saatnya bersuami, namun dinda, masih mengekang kehendak, supaya tidak cepat tua, mari kita menikah. ( Pupuh Pangkur bait 16 )

Tokoh Gusti Ngurah Sibetan digambarkan sebagai sorang pemuda yang kuat dan pemberani. Seperti terlihat dalam kutipan berikut:

Sujatine ragan cening mula teguh, duh kapan ada nyedanin, Kadi Bima dadi caru, pacang mamelanin gumi, di Payudan boya kasor.

Terjemahan :

Sesungguhnya dirimu memang kuat, mustahil akan ada yang bisa membunuh, seperti Bima yang menjadi caru, akan membela negara tidak akan kalah di medan perang. ( Pupuh Megatruh bait 22 )

Selanjutnya perwatakan tokoh sekunder pertama yaitu Gusti Nyoman Banjar. Tokoh Gusti Nyoman Banjar secara fisikologis digambarkan sangat tampan dan sangat diidolakan para wanita. Hal ini terdapat dalam bait berikut :

Rainé kekalih kecap, sedeng truna tur apekik, dados kakidungan bajang, sing kenyemin sinah buduh, dané Gusti Nyoman Banjar, lan sang ari, dané Gusti Ketut Bona.

Terjemahan :

Konon mempunyai dua adik, beranjak dewasa dan tampan, yang menjadi dambaan gadis-gadis, tiap tersenyum membuat tergila-gila, namanya I Gusti Nyoman Banjar, dan adiknya, I Gusti Ketut Bona. (Pupuh Ginada bait 7)

Selanjutnya tokoh komplementer dalam Geguritan cokli antara lain : Gusti Ketut Bona, Gusti Ayu Rai, Ayu Raka, 
Ni Pudak, Ni gambir, Mangku Jarni, Pan Jarna, Ibu Perami, Mangku Nesa, Mangku Pasek, I Gading dan I Nohan, Ki Pasek Anom, Krama Banjar Luh, Ki Bendesa, Gusti Ayu Pande, Gusti Ketut Banjar, Raja Bangli, I Gusti Gede Taman, Gusti Wayan Taman, Gusti Ketut Sibetan, Sang Pandita, Gusti Made Jelantik, Gusti Made Bona.

\section{Latar}

Latar (setting) adalah tempat atau terjadinya cerita, pada hakekatnya suatu cerita merupakan lukisan peristiwa atau kejadian-kejadian yang dilukiskan oleh satu atau beberapa tokoh pada suatu dan di suatu tempat (Suharianto, 1982). Latar tempat dalam Geguritan cokli Geguritan Cokli yang menjadi lokasi tempat terjadinya peristiwa antara lain : Dalem Jawi, Pura Pucaksari, Beji (tempat pemandian), Jero, Mrajan Dalem Jawa (kemulan), Mrajan Agung, Mrajan Alit, Jero Gusti Ngurah Sibetan, Panyabangan, Pancoran, Natar Pura Pucaksari, Bale Agung, Dusun Iseh, Telengis, Bunteh, Dusun Palamadon, Bale Loji, Pura Pusar Tasik, Pura Pasar Agung, di Tirta, di Gria Dang Guru, dan di Pura Taman Sari. Sedangkan, latar waktu antara lain : bulan ketiga pada hari Saraswati, pagi hari, malam bulan purnama, sasih kapat, tilem ketujuh ( Siwa Ratri ).

\section{Tema}

Tema merupakan ide pokok sebuah cerita dan merupakan hal yang terpenting dalam cerita sebagai tujuan yang ingin disampaikan pengarang kepada pembaca lewat karyanya. Tema Geguritan Cokli adalah kisah percintaan tak sampai antara Gusti Ayu Cokli dengan Gusti Ngurah Sibetan yang dikarenakan Gusti Ayu Cokli masih menjalani masa Brahmacari. Hingga pada akhirnya kisah mereka pupus begitu saja karena Gusti Ayu Cokli meninggal dan Moksa karena ketekunannya dalam masa menuntut ilmu pada masa Brahmacari.

\section{Amanat}

Menurut (Esten, 1978) setiap karya sastra pasti mempunyai amanat yang merupakan tujuan dari penulisan cerita. Di dalam amanat tercermin pandangan hidup dan cita-cita pengarang. Amanat dapat diungkapkan secara implisit (tersirat) dan dapat pula secara eksplisit (tersurat).

Adapun amanat yang ingin disampaikan pengarang dalam Geguritan ini adalah menjujung tinggi nilai kesetiaan hal ini dibuktikan dalam tokoh Gusti Ngurah Sibetan yang sangat setia menunggu Ayu Cokli yang sedang menuntut ilmu. Amanat lain yang dapat kita petik adalah apapun yang kita lakukan dengan keseriusan dan sepenuh hati pasti hasil yang akan dicapai sangat memuaskan. Hal ini terlihat dari keseriusan Gusti Ayu Cokli mempelajari ajaran-ajaran yoga hingga akhirnya ia pun memperoleh kesempurnaan tertinggi yaitu Moksa.

\section{Analisis Sosiologi Sastra Geguritan Cokli}

Analisis sastra secara sosiologis didasarkan atas prinsip bahwasanya fakta sastra adalah fakta mengenai nilai-nilai (Atmaja, 1988). Bersama dengan itu nilai yang terkandung dalam sastra dipandang sebagai aspek nilai yang harus terkandung di dalam sastra, karena ia merupakan aspek yang khas dari teks sastra. Berdasarkan pengertian tentang sosiologi di atas yang banyak memuat masalah-masalah sosial budaya dalam masyarakat, maka akan dipaparkan beberapa aspek sosiologis dari Geguritan Cokli antara lain: 1) Aspek Agama; 2) Aspek Estetika; 3) Aspek Kemasyarakatan: 4) Aspek Kesetiaan.

\section{Aspek Agama}

Agama merupakan kepercayaan akan adanya kuasa atas segala yang ada yang disebut Tuhan, serta segala sesuatu yang 
bersangkut paut dengan kepercayaan itu (Sura, dkk:1998). Adapun aspek-aspek agama yang terkandung dalam Geguritan cokli adalah adalah percaya dengan keberadaan Tuhan dengan segala manifestasinya, seperti terdapat dalam kutipan berikut:

Sane malinggih ring pura, wantah Sang Hyang Pasupati, ne ngamelang alam donyo, nguripang sarwa tumuruh, ngicalang wateking mala, napi malih, ngutah mising miwah kacacar.

Terjemahan :

Yang berstana di pura, tiada lain adalah Sang Hyang Pasupati, beliau yang menguasai alam semesta, menghidupkan mahluk hidup, menghilangkan segala kekotoran, apalagi penyakit muntaber dan cacar. (Pupuh Ginada bait 3)

Dari kutipan di atas tampak jelas bahwa Tuhan disebut dengan banyak nama seperti Sang Hyang Pasupati yang dianggap berstana di Pura Dalem Jawi, Sang Hyang Pasupati yang memberikan kehidupan pada semua mahluk hidup di dunia. Namun tetap mengacu pada satu hal atau tujuan yakni Tuhan Yang Maha Esa. Menurut konsepsi agama Hindu Tuhan itu Maha Sempurna, kekuasaanya tak terbatas, segala sesuatu yang ada berasal dari pada-Nya karena itu Beliau disebut Sang Hyang Sangkan Paraning Sarat, berarti apapun yang kita persembahkan kepada beliau sematamata merupakan cetusan maha terima kasih kita kepada-Nya (Badjera Yasa, 1982:7). Salah satu wujudnya itu adalah dengan menghaturkan sesajen atau banten, seperti terdapat dalam kutipan berikut ini :

Bebantenan, katur ring suang-suang pelinggih, canang wewangian, daksina muah reresik, ajuman lan patirthaan.

Terjemahan:

Banten-banten, dipersembahkan di masing-masing pelinggih, canang wangi-wangian, daksina dan reresik, ajuman dan petirthaan. (Pupuh Kumambang bait 22)

Dari kutipan diatas sangat jelas salah satu cara kita berterima kasih kepada Tuhan adalah dengan menghaturkan sesaji atau banten di tempat-tempat yang dianggap suci. Selain hari atau setiap hari tertentu umat Hindu biasanya melakukan persembahyangan di tempat-tempat suci sebagai wujud rasa terima kasih.

Selain itu juga terkandung ajaran Susila. susila mengandung arti perbuatan (laksana, tingkah laku) yang baik. Seperti terdapat dalam kutipan berikut:

Inggih ratu galahe sampun prapti, ngalebarang, rarisang cacaran sane patut icen plancahan, kelapa wohwohan taluh, icen sane pinih kelih, ipun pastika margiang, maring kadang margin ipun, bojoge nunas labaan, sami natak, ngawit saking pinih alit, samian polih eduman.

Terjemahan:

Baiklah tuanku, waktunya sudah tiba, mempersembahkan sajen, silahkan bagikan, yang pantas diberi binatang keramat, kelapa buahbuahan telor, berikan yang paling tua, dia pasti membaginya, kepada suku jenisnya, keranya memakan sesajen, semuanya menadahkan tangan, dari yang paling kecil, semua mendapat bagian. (Pupuh Dangdang bait 10)

Dari kutipan diatas terlihat bahwa konsep Tat Twam Asi sudah berjalan, dimana Gusti Ayu Cokli membagikan sajen kepada binatang-binatang dan binatang-binatang itupun membagikan sajen itu kepada teman-temannya. Inilah yang dijadikan perbandingan pada manusia yang selalu mementingkan diri sendiri yang selalu diliputi oleh rajah dan tamah yang sangat bertentangan dengan ajaran Tat Twam Asi. Selain ajaran Tat Twam Asi juga terkadung ajaran Tri Kaya 
Parisudha Trikaya Parisudha, terdiri dari kata Trikaya yang artinya tiga dasar perilaku manusia dan Parisudha berarti yang harus disucikan. Jadi Trikaya Parisudha adalah tiga macam perilaku yang harus disucikan, yaitu manacika (pikiran), wacika (perkataan) dan kayika (perbuatan). Seperti terdapat dalam kutipan berikut:

Yadin berat, yan dasarin baan lascarya, Trikaya lan Tat Twam Asi, sami parisudha, ngawit saking pakayunan, bebaos laksana yukti, patut tegegang, mangda bresih miwah suci.

Terjemahannya :

Walaupun berat, kalau didasarkan dengan ketulusan, Tri Kaya dan Tat Twam Asi, semua suci, bermula dari pikiran, perkataan dan perbuatan, harus dilaksanakan, agar bersih dan suci. (Pupuh Durma bait 10)

Dari kutipan diatas jelas terlihat dalam melaksanakan ajaran Tat Twam Asi dan Tri Kaya Parisudha harus berdasarkan pada ketulusan hati. Dari ajaran Trikaya Parisudha ini maka timbullah sepuluh pengendalian diri yaitu,

Tiga macam yang berdasarkan pikiran :

1. Tidak mengingini sesuatu yang tidak halal

2. Tidak berfikir buruk terhadap mahluk lain

3. Tidak mengingikari akan karmaphala.

Empat macam berdasar pada perkataan :

1. Tidak suka mencaci maki.

2. Tidak berkata kasar pada mahluk lain.

3. Tidak memfitnah

4. Tidak ingkar pada janji atau ucapan.

Tiga macam pengendalian berdasar perbuatan :

1. Tidak menyiksa atau membunuh mahluk lain.
2. Tidak melakukan kecurangan terhadap harta benda

3. Tidak berjinah. (Upadesa, 2001)

\section{Aspek Estetika}

Kata estetika dalam Kamus Besar Bahasa Indonesia diartikan cabang filasafat yang menelaah atau yang membahas tentang seni dan keindahan, serta tanggapan manusia terhadapnya (1990: 236). Keindahan pada suatu karya sastra terletak pada keindahan bahasa yang dibentuk melalui bahasa kiasan. Jadi dapat disimpulkan estetika merupakan suatu aspek keindahan yang terdapat dalam karya sastra, baik dalam pemilihan kata serta bahasa dalam sebuah karya sastra.

Geguritan Cokli merupakan hasil karya sastra, yang di dalamnya juga mengandung aspek-aspek estetika. Aspek-aspek tersebut dalam geguritan Cokli secara eksplisit dan implisit dapat dilihat dalam penggunaan bahasa yang dipakai oleh pengarang, sangat sederhana dan indah untuk dibaca sehingga memudahkan untuk mengetahui isinya. Selain itu dalam geguritan ini juga terdapat gaya bahasa personifikasi. Gaya bahasa personifikasi adalah semacam gaya bahasa kiasan yang menggambarkan benda-benda mati bertindak, berbuat, berbicara seperti manusia (Keraf:1986). Seperti terdapat dalam kutipan berikut :

Pasar Agung kanten mateja dumilah, napi malih Pura Besakih, rasa maangkihan, andus dupane ngambara, malepug ngantos kalangit, nuhur Bhatara, mangda tedun manywecanin.

Terjemahan :

Pasar Agung, terlihat menyala, apalagi pura Besakih, terasa bernafas, asap dupanya ke langit, mengepul sampai ke angkasa, memanggil para Dewa, agar turun memberikan berkah. ( Pupuh Durma bait 21 ) 
Selain gaya bahasa personifikasi juga terdapat gaya bahasa hiperbola. Gaya bahasa hiperbola adalah gaya bahasa yang mengandung pernyataan yang berlebih-lebihan dari segi jumlah, ukuran, atau sifat dengan maksud memberi penekanan pada suatu pernyataan atau situasi, guna memperhebat/meningkatkan kesan dan pengaruhnya. (Tarigan, 1985).

Marep kauh, gunung teromponge sawat, Batukaru kanten rawit, kadi sebun ujan, nganyomin jagat Tabanan, rauhing ka Baturiti, gemuh raharja, satmaka jinenging Bali.

Manyoreang, Sang Hyang Surya ngarorokang, kanten kadi taluh besi, barak kapanesan, masebun gulem temaga, warnane tangi lan kuning, masawang abang, kadi langse Badung yukti.

Terjemahan

Menghadap barat, gunung Terompong di kejauhan, Batukaru terlihat rapi, bagai sarang hujan, yang mengayomi wilayah Tabanan, sampai ke Baturiti, sangat suburbagaikan lumbung Bali. (Pupuh Durma bait 24)

Sore hari, matahari semakin tenggelam, kelihatan bagai telur besi, merah kepanasan, bersarangkan mendung tembaga, warnanya ungu dan kuning, agak kemerahan, seperti langse Badung. (Pupuh Durma bait 25)

\section{Aspek Kemasyarakatan}

Ilmu yang mempelajari kemasyarakatan disebut sosiologi. Sapardi Djoko Damono menyatakan bahwa sosiologi ialah telaah yang objektif dan ilmiah tentang manusia dalam masyarakat, telaah tentang lembaga dan proses sosial. Sebuah karya sastra tidak dapat dipahami selengkaplengkapnya apabila dipisahkan dari lingkungannya atau peradaban yang menghasilkannya. Sastra harus dipelajari dalam konteks yang seluas-luasnya dan tidak hanya dirinya sendiri. Aspek kemasyarakatan yang tergambarkan dalam geguritan cokli adalah tradisi perkawinan dalam adat Bali dan tradisi magibung.

Perkawinan adalah ikatan lahir batin antara seorang pria dengan seorang wanita sebagai suami istri dengan tujuan membentuk keluarga (rumah tangga) yang bahagia dan kekal berdasarkan Ketuhanan Yang Maha Esa (Surpha Dalam Proyek Bimbingan dan Penyuluhan kehidupan Beragama Tersebar di 9 (Sembilan) Dati II, 1994/1995:5 ).

Dalam geguritan Cokli disebutkan beberapa macam tradisi perkawinan yang terdapat di Bali, seperti terdapat dalam kutipan berikut :

Indik tingkah pawarangan, sami suka, ngarorod miwah mapadik, gandarwa wiwaha patut, nanging wenten pesaksian, Hyang Ageni, mlegandang sane tan patut, mamitra ngalang impasang, ngawe leteh kawastanin.

Terjemahan :

Mengenai tata cara perkawinan, semuanya bahagia, ngarorod dan mapadik, gandarwa wiwaha semuanya benar, namun harus ada saksi, Dewa Api, mlegandang yang tidak benar, mamitra, disebut perbuatan kotor. ( Pupuh Pangkur bait 50 )

Dari kutipan diatas disebutkan ada jenis-jenis perkawinan yang lumrah dikenal oleh masyarakat Bali yaitu, ngarorod dan mapadik. Ngarorod adalah sistem perkawinan berdasarkan cinta sama cinta dari kedua calon mempelai, dengan alasan sebagai berikut : (a) tidak mendapat restu dari salah satu pihak orang tua mempelai; (b) tidak mendapat restu orang tua kedua mempelai; (c) Dilaksanakan sistem perkawinan ini berdasarkan efisiensi pelaksanaan dan pembiayaan; (d) Dilaksanakan sistem perkawinan ini berdasarkan pemikiran 
bahwa dari kedua belah pihak tidak lagi memiliki sanak keluarga atau salah satu pihak tidak memiliki sanak keluarga. (Sudarsana, 2002).

Sedangkan mapadik adalah sistem perkawinan yang dilandasi oleh rasa cinta sama cinta dari kedua calon mempelai serta mendapat restu dari kedua belah pihak orang tua (Sudarsana, 2002:8). Mlegandang adalah sistem perkawinan yang dilakukan dengan cara kekerasan, yaitu calon mempelai wanita dikawini dengan cara paksa. Dilihat dari pelaksanannya perkawinan ini mempunyai beberapa istilah, yaitu: (1) Angayab, seorang laki-laki mngambil calon mempelai wanita secara paksa ketika menonton dengan tujuan dikawini; (2) Angateli, seorang laki-laki mengambil calon mempelai wanita secara paksa ketika si wanita sedang tidur; (3) Alamat, calon mempelai laki-laki mengambil calon mempelai wanita secara paksa dihadapan banyak kaum keluargannya; (4) Amerugu, seorang lakilaki mengambil calon mempelai wanita secara ketika mandi; (5) Amerekeneng, seorang laki-laki mengambil secara paksa calon mempelai wanita ketika seorang berkutu; (6) Amengmengin, seorang lakilaki mengambil calon mempelai wanita secara paksa ketika sedang bermainmain. (Arnati, 2002).

Selanjutnya adalah tradisi magibung. Magibung berarti makan bersama dalam satu hidangan (nasi, lauk, pauk dalam satu tempat). Gibungan berarti hidangan untuk makan bersama atau makanan untuk disantap bersama-sama delapan orang yang duduk melingkar mengitari gibungan tersebut (Kersten, 1984). Istilah magibung sebenarnya mempunyai banyak pengertian. Makan bersama pesertanya lebih dari seorang juga disebut magibung (Rupa, 2003).

Tradisi magibung ini juga dilukiskan dalam Geguritan Cokli seperti terdapat dalam kutipan berikut :
Pemaksane taler magibung sami, sapisanan, wenten malagaran, nunas sajeng datengane, matimpal lawar lan balung, arake matimpal sate, urutan miwah serapah, tetimbungan babi gebuh, anggen taled magonjakan, kapah-kapah, gilirane nganem sasih, dados saya madatengan.

Terjemahan :

Pemaksan pun juga semuanya magibung, sekalian, ada makan tanpa lauk pauk, para tamu minum, dengan lawar dan balung, arak dengan sate, urutan dan serapah, tetimbungan babi empuk, dipakai alas bersenda gurau, jarang-jarang, gilirannya enam bulan, menjadi juru mempersembahkan sesajen. (Pupuh Dangdang bait 18)

\section{Aspek Kesetiaan}

Kesetiaan berasal dari kata setia (satya) mendapat konfiks ke-an, yang berarti kebenaran atau kejujuran. Dalam Agama Hindu kita mengenal lima macam satya yang sering disebut dengan Panca Satya: Satya Hredaya yakni setia pada pikiran sendiri, Satya Wacana yakni setia pada ucapan, Satya Semaya yakni setia pada janji, Satya Mitra yakni setia pada teman, Satya Laksana yakni setia pada perbuatan (Wijaya, 1981: 115). Dari kelima Satya diatas dalam Geguritan Cokli ini hanya terdapat tiga Satya yaitu satya hredaya, satya wacana, dan satya semaya.

Pelukisan tentang satya hredaya juga terdapat dalam Geguritan Cokli sperti terdapat dalam kutipan berikut :

Kaden sampun, ping kuda titiang matur, ledang manyantosang, reh kadung titiang majanji, maring kahyun, pacang muputang malajah.

Terjemahan:

Kan sudah, beberapa kali hamba katakan, tunggulah, karena hamba terlanjur berjanji, pada pikiran sendiri, akan menyelasaikan belajar. (Pupuh Pucung bait 32) 
Selanjutnya pelukisan terhadap ajaran satya wacana yaitu setia pada perkataan juga terdapat dalam geguritan Cokli seperti terdapat dalam kutipan berikut :

Tan sue lantas Ida masurudayu, lanang isteri dados Rsi, kadiksa olih Dang Guru, kadi pangaptine nguni, yukti satya ring bebaos.

Terjemahan :

Tidak lama kemudian beliau ditasbih, suami istri menjadi Resi, disahkan oleh Sang Guru, seperti janjinya dahulu, harus setia terhadap perkataan. (Pupuh Megatruh bait 31)

Dan yang terakhir adalah Selanjutnya adalah Satya Semaya yaitu setia pada janji, dalam Geguritan Cokli juga dipaparkan tentang satya semaya seperti terdapat dalam kutipan berikut:

Uduh cening ampurayang ingsun, tan kirang tuture, mangda satya teken janji, talin manusa punika, wantah baos sane sadhu, gilik sareng laksanane, yen yukti magama Hindu, Trikaya Parisudane, Panglukatan Dasa Mala.

Terjemahan :

Oh ananda maafkan saya, tak kurang nasehatnya, supaya setia terhadap janji, itu merupakan jalinan persahabatan manusia, hanya perkataan yang jujur, sesuai dengan perilakunya, jika sungguh beragama Hindu, Trikaya Parisuda, sebagai pembersih Dasa Mala. (Pupuh Adri bait 9)

\section{SIMPULAN}

Berdasarkan pemaparan di atas dapat disimpulkan bahwa, sebagai sebuah karya sastra khususnya Geguritan Cokli ini memiliki struktur naratif yang utuh dan lengkap dan berkaitan satu dengan yang lain. Begitu pula dengan proses kepengarangan suatu karya sastra sangat berkaitan dengan keadaan masyarakat saat karya tersebut tercipta. Keadaan social masyarakat inilah dituangkan oleh tangan dan intuisi kreatif seorang pengarang. Walaupun karya sastra lahir dari lingkungan sosial zamannya, bukan berarti sastra itu adalah kenyataan sosial. Begitu pula dengan geguritan Cokli ini, ada persamaan dan perbedaan antara karya sastra dengan keadaan social masyarakat saat itu. Persamaannya adalah nilai-nilai luhur yang mencakup ajaran-ajaran kebaikan dari dahulu hingga kini masih sangat relevan diterapkan dalam kehidupan masyarakat. Sedangkan perbedaannya adalah ada beberapa pelukisan nilai-nilai yang sudah tidak relevan lagi dengan perkembangan zaman, hal ini tidaklah mengherakan karena karya ini adalah bentuk transpormasi dari satua orang tua pengarang yang kemudian dituliskan kembali dalam bentuk geguritan. Karya Geguritan Cokli adalah sebuah karya sastra yang menarik dan layak dianalisis dari berbagai persfektif baik itu dari kebahasaannya atau kesusastraannya.

\section{DAFTAR PUSTAKA}

Agastya, Ida Bagus Gede. (1980). Geguritan Sebuah Bentuk Karya Sastra Bali, untuk Sarasehan Sastra Daerah Pesta Kesenian Bali ke-2 9 Juli 1980. Denpasar.

Aminuddin. 1987. Pengantar Apresiasi Karya Sastra. Bandung : Sinar Baru Offset.

Bagus, I Gusti Ngurah. (1991). Fungsi Sosial Geguritan dalam Masyarakat Bali. Denpasar : Fakultas Sastra UNUD.

Damono, Sapardi Djoko. (1978). Sosiologi Sastra Sebuah Pengantar Ringkas. Jakarta : Pusat Pembinaan dan Pengembangan Bahasa 
Departemen Pendidikan dan Kebudayaan.

Damono, Sapardi Djoko. (1979). Novel Sastra Indonesia sebelum Perang. Jakarta : Pusat Pembinaan dan Pengembangan Bahasa Departemen Pendidikan dan Kebudayaan.

Damono, Sapardi Djoko. (2002). Pedoman Penelitian Sosiologi Sastra. Jakarta : Pusat Bahasa Departemen Pendidikan Nasional.

Faruk. (1994). Pengantar Sosiologi Sastra. Yogyakarta : Pustaka Pelajar.

Keraf, Gorys. (1984). Diksi dan Gaya Bahasa. Jakarta: PT. Gramedia.

Kersten, J. S. V. D. (1984). Bahasa Bali, Tata Bahasa : Kamus Bahasa Lumrah. Flores : Nusa Indah.

Pradopo, Djoko Rachmat dkk. (2001). Metodologi Penelitian Sastra. Yogyakarta : PT. Hanindita Graha Widia.

Soekanto, soerjono. 1987. Sosiologi Suatu Pengantar. Jakarta. Rajawali Press.

Suastika, I Made. (1985). “Aspek Sosiologi Cerita Pan Balang Tamak" dalam Majalah Ilmiah Universitas Udayana.

Sudarsana, I. B Putu. (2002). Ajaran Agama Hindu (Makna Yang Terkandung Dalam Upacara Perkawinan Hindu). Yayasan Dharma Acarya : Percetakan Mandara Sastra.

Suharianto, S. (1982). Dasar-Dasar Teori Sastra. Surakarta : Widuaduta
Sukada, I Made. (1982). Masalah Sistematika Analisis Cipta Sastra. Yayasan Ilmu dan Seni Lembaga Seniman Indonesia Bali. Cetakan ke2. Denpasar: Gema.

Teeuw, A. (1984). Sastra dan Ilmu Sastra Pengantar Teori Sastra. Jakarta: Gramedia.

Wellek, Rena \& Austin Warren. (1948). Teori Kesusastraan. Jakarta : PT Gramedia.

Wenten, I Gede. (1973). Pendidikan agama Hindu. Singaraja : TB. Indrajaya.

Wijaya, I Gede. 1981. Pengantar Agama Hindu untuk SMTA. Denpasar : Setia Kawan 